\title{
More university reforms needed
}

\section{Barcelona}

THERE are said to be two national spectacles in Spain, bullfights and "oposiciones", the recruiting system for the civil service. It is a matter of discussion which one is the bloodier. Reforms in access to university and CSIC (Spanish Science Research Council) positions have modified the "oposiciones", but recent experience suggests that some of the most controversial elements of the system still exist.

Spanish professors and researchers in public institutions are considered as civil servants and therefore have permanent tenure, which tends to create lethargy in many Spanish institutions. That was certainly the opinion, before coming to power, of many members of the Socialist Party, now starting its second four-year term in Spanish central government. Recent regulations have led to invited professors and research staff recruited on short-term contracts. The reforms introduced in universities and in CSIC in the past four years have, however, maintained the traditional civil service system and the selection by "oposiciones".

The spectacle itself is much less colourful than it used to be. The "oposiciones", in the nineteenth-century tradition but modified in the 1930s during the Second Spanish Republic, used to be a series of public examinations, theoretical or practical, designed to choose the ablest candidate for the job. Now, a candidate has to pass only two examinations, one on his personal curriculum and the second on a subject related to his field of research. A committee formed for every position or groups of similar positions makes its decision by voting and without appeal. The committee can put any kind of questions to the candidate. In some cases, the experience may be traumatic for candidates, committees (which may sit for weeks before reaching a decision) and for departments.

The Law for University Reform has introduced two important modifications. One is that universities now have the right to appoint two of the five-member committee that selects the candidates; the other three members are chosen by a computer at random from the list of professors of the same field.

The second change is that university departments may propose a "profile" of the candidate. The experience of the past two years shows that the result has normally been to slant appointments to specific people already working in the same department. The actual result is an increase in in-breeding in university departments and many people are worried about the long-term consequences. Hundreds of new positions are being advertised as a consequence of the Law of University Reform; for example, the Autonomous University of Barcelona has had nearly 300 new positions in 1986 alone. But the rules may be modified in the near future in the light of experience.

In CSIC, the system shows some important differences. On the one hand, positions are advertised once a year and relate to specific institutes and specific subjects; on the other hand, since last year, all committee members are appointed by the president of CSIC and often include members of university departments as well as CSIC staff. In each of the past two years, about 200 positions have been advertised, after a long time without openings. Last year around 400 candidates applied for the positions. In some fields such as molecular biology, there were four candidates for each position,

which means that in many cases only one candidate applied, or none. This result has been interpreted as showing the need for a long-term policy for recruiting research personnel and for attracting scientists now working abroad. New statutes for CSIC are expected to be issued before the end of this year that will include a different structure for research staff.

The "oposiciones" was a system designed more than a hundred years ago to make Spanish public administration more accessible. It has been widely recognized that a new system would be needed before the end of the twentieth century to select the appropriate people for research or universities. But the rules of Spanish administration are difficult to change, and the recent regulations have tried to adapt an obsolete system to modern Spanish society.

It is generally felt in universities and CSIC that further steps are needed in any case to achieve a flexible and efficient recruiting system for Spanish higher education and research. Pedro Puigdoménech

\section{India}

\section{Space programme uncertainty}

New Delhi

INDIA is still not sure when or how to get its multipurpose Insat I-C satellite launched into geostationary orbit to provide continuity in its space-based meteorological, television and telecommunications services.

Under a contract with the US National Aeronautics and Space Administration (NASA), the satellite, along with an Indian payload specialist, was to have been carried by the space shuttle this month. The indefinite postponement of shuttle flights after the Challenger explosion, and uncertainty about the availability of the alternative Delta rockets, has upset the schedule of the Indian Department of Space (DOS).

According to DOS secretary Professor U.R. Rao, negotiations are now going on with the European Space Agency for Insat 1-C to be accommodated in one of the Ariane launches before the end of 1987 . With Ariane solidly booked for the next two years, and with its own schedule upset by the failure of the Ariane-IV launch in March, it is likely that Insat 1-C may not leave the ground before 1988 . India's only functioning satellite, Insat $1-B$, has been taking the full work load since August 1983 after its companion, Insat 1-A, was disabled by on-board power failure. The US Ford Aerospace Corporation, which built the three satellites for India, has been asked to deliver a fourth. Insat 1-D, by 1988 .

Continuity of the satellite service is important, for India now relies significantly on Insat 1-B for weather forecast, television broadcast and telephone links be- tween remote places. The satellite provides 4,000 two-way telephone circuits and has helped to network India's 173 television and 91 radio stations, as well as beaming television programmes directly to 2,000 community receivers in villages and relaying educational programmes to 1,953 schools and 62 colleges.

Insat 1-B is the only geostationary satellite over the Indian Ocean providing meteorological images to the world, and duplicate Insat weather data are supplied daily to the United States. Apart from ensuring continuity of services, India is anxious to get Insat 1-C launched as soon as possible to avoid possible political complications arising out of delay in occupying the allotted slot in the geostationary orbit. India will continue to rely on foreign launchers, as it is unlikely to be able itself to put satellites into geosynchronous orbit before the year 2000 .

Insat $1-\mathrm{C}$ is not the only project beset by delay. The test flight of the Augmented Satellite Launch Vehicle (ASLV), designed to lift a $150-\mathrm{kg}$ payload, was scheduled for last year but has yet to take place. The launch of an Indian-built remote-sensing satellite from the Soviet Union, scheduled for September this year, has been postponed. India's only operational rocket, SLV-3, has not flown for the past two years.

According to DOS, the destruction of major facilities at its east coast Sriharikota launch complex is one reason for the slowdown of space activities. The complex was damaged in a cyclone two years ago and plans are afoot to shift it to a safer location. 